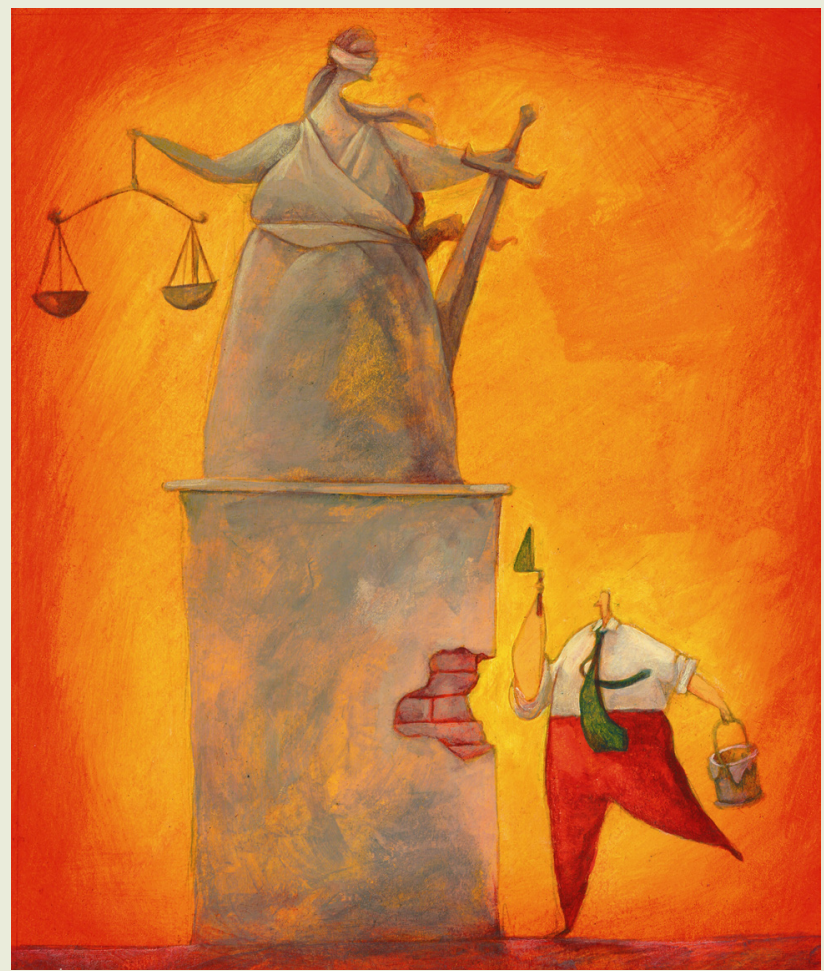

\title{
Auxiliares de la
} Administración de Justicia: ¿Monopolios de Privilegio?

\section{Introducción}

Desde fines de los años 90 se ha venido implementando en Chile un conjunto de reformas para modernizar nuestras instituciones de justicia. Entre ellas las reformas a la justicia penal, laboral, de familia, de defensa de la libre competencia y, próximamente, la civil. Sin embargo, un área importante, la de sus organismos auxiliares, permanece anquilosada y requiere de una profunda revisión para determinar qué aspectos de ella requieren ser modernizados.

Los 'auxiliares de la administración de justicia' incluyen un amplio abanico de personajes: notarios, conservadores, archiveros, receptores y otros de no tan extendida fama, como los procuradores del número y los defensores públicos. ${ }^{1}$ Ellos cumplen diversos roles. En algunos casos otorgan validez y registran actos jurídicos de relevancia para la vida social; en otros, actúan como representantes de la fe pública respecto de determina- das transacciones y, en ocasiones, cooperan con la función jurisdiccional de los tribunales. Varios de estos roles buscan entregar certidumbre a las relaciones jurídicas y a los derechos de propiedad. Este artículo se centra en los notarios y conservadores; analiza las funciones y naturaleza de ambos roles y ofrece algunas sugerencias para mejorarlas.

Los siguientes datos sirven como información inicial sobre el interés y relevancia de este tema. Un estudio reciente ${ }^{2}$ ha estimado la utilidad operacional anual, antes de impuestos, del Conservador de Bienes Raíces de Santiago (CBRS) en torno a US\$ 8 millones, lo que equivale a unos 350 millones de pesos de utilidad operacional bruta mensual, o un margen de ganancia operacional de $61,5 \%$. Si consideramos un periodo de 20 años y una tasa de descuento de $8 \%$ real anual, estos flujos de ganancia equivalen a un valor de capital de 85 millones de dólares. Ahora bien: desde el punto de vista de una persona que compra un inmueble a su nom-

Julio Peña Torres*

Javier Velozo Alcaide*

\footnotetext{
* Académico de la Facultad de Economía y Negocios, Universidad Alberto Hurtado, Doctor en Economía, Universidad de Londres.

** Abogado y Profesor de la Facultad de Derecho, Universidad Alberto Hurtado, Doctor @ en Economía de las Instituciones, Universidad Complutense de Madrid.

Los antiguos, no los introducidos por la Reforma Procesal Penal.

P. Abarca (2006), "El Conservador de Bienes Raíces de Santiago", Memoria para optar al título de Ingeniero Civil, PUC, Stgo. Este estudio estima ingresos operacionales anuales en torno a los US\$13 millones para dicho conservador. Para estimar los costos operacionales totales (que incluyen diversos costos variables, gastos de administración, gastos de servicios externos y otros gastos fijos -incluyendo arriendo de edificio, bodegas y costo de seguros-) utiliza una metodología tipo "empresa modelo o eficiente".
} 
este artículo buscamos aportar intuiciones y análisis al respecto.

\section{Que las características de cupos limitados y validez vitalicia del puesto de notario se hayan perpetuado en el tiempo, aún después de cesar la exigencia de pagar para adquirir este privilegio, al menos en forma explícita y legal, podría tal vez explicarse por una exitosa captura del regulador, que efectúa el grupo privado favorecido.}

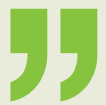

\section{Los notarios}

La ley chilena les da el carácter de ministros de fe pública. En esa calidad, están encargados de certificar la realidad o veracidad de hechos, dar legitimidad a determinados negocios jurídicos y dejar testimonio de ellos en registros. En cada comuna o grupo de comunas que constituyen el territorio de un juez de letras existe a lo menos un notario. Hay 306 notarios en todo el país, lo que corresponde a unos 50.600 habitantes por notario. En Santiago, unos 40 notarios atienden a una población de casi seis millones de habitantes (lo que implica unos 150.000 habitantes por cada notario).

Los notarios no son formalmente funcionarios de la administración del Estado, pero están afectos a un régimen disciplinario y sujetos al sistema de calificaciones del Poder Judicial. Tienen un territorio asignado para ofrecer sus servicios. Los precios a cobrar por sus prestaciones están definidos según aranceles que, cada cierto número de años, les fija el Poder Judicial. Además, pueden pactar remuneraciones convencionalmente con los usuarios para servicios profesionales distintos al de ministro de fe, como el de asesoramiento o redacción de documentos.

Existen tres categorías que diferencian a las notarías según su importancia y ubicación. Así, es posible ascender en una suerte de "carrera notarial" postulando, con cierta preferencia frente a interesados ajenos a la función, a las vacantes. ${ }^{3}$ Determinadas áreas geográficas son especialmente privilegiadas en cuanto al volumen y complejidad de los trámites que en ella se realizan (como el centro de Santiago).

\section{Cupos limitados y cargos 'de por vida': ¿Por qué?}

En Chile los notarios son designados por el Presidente de la República, a partir de una terna propuesta por la Corte de Apelaciones respectiva. Luego de un aviso en el Diario Oficial que informa la apertura de un proceso de selección, los interesados seleccionados son entrevistados por los ministros de la corte respectiva, la que posteriormente confecciona la terna que se envía para el nombramiento presidencial. Este proceso de selección es poco transparente y no está sujeto a mecanismos de control que garanticen una evaluación meritocrática y objetiva de los postulantes. Tampoco es evidente por qué en este ámbito de decisión se requiere necesariamente la intervención presidencial.

El cargo de notario, hasta el año 1995, era vitalicio. Una reforma introducida ese año estableció que duran en sus puestos hasta que cumplan 75 años (esta norma sólo se aplica a los notarios que hayan sido nombrados por primera vez después de ese año). Dado que la edad requerida por ley para este nombramiento es de 25 años, el sistema permite que una persona sea notario durante 50 años.
El sistema de nombramientos y promociones de los notarios involucra discrecionalidad en el otorgamiento de un privilegio. ${ }^{4}$ Es probable que esta forma de designación, junto con el número limitado de cupos, tenga un origen histórico.

En la tradición del derecho hispano, el rol de notario fue durante mucho tiempo un oficio desempeñado por particulares que accedían al cargo -de forma vitalicia- comprando el derecho a ejercerlo. En la época de los Reyes Católicos, los escribanos, que eran funcionarios reales con un rol equivalente al notario moderno, pagaban a la corona por el privilegio de serlo. Con posterioridad, al menos en la tradición jurídica continental de origen latino y de la mano de la codificación impulsada por la revolución francesa y Napoleón, el nombramiento y ejercicio de la función notarial pasó a ser regulada por el Estado.

Desde el punto de vista recaudatorio de la autoridad que vendía tales derechos, el hacerlo en un número limitado y de forma vitalicia probablemente maximizaba la recaudación a obtener por dicha venta. Así, se entregaba un monopolio de privilegio a cambio de recaudar rentas.

Lo anterior sería consistente con la tesis sugerida por el gran historiador francés Fernand Braudel: el apoyo estatal a la entrega de derechos monopólicos con frecuencia ha formado parte de operaciones fiscales motivadas por las dificultades financieras que suelen constituir el "veneno perpetuo de los estados modernos'. 5

Ahora bien, en la actualidad, los notarios cumplen una función para la que existe demanda 'garantizada' por ley. En efecto, la demanda por servicios notariales nace, la mayor parte de las veces, por requerimientos legales. Que las características de cupos limitados y validez vitalicia del puesto de notario se hayan perpetuado en el tiempo, aún después de cesar la exigencia de pagar para adquirir este privilegio, al menos en forma

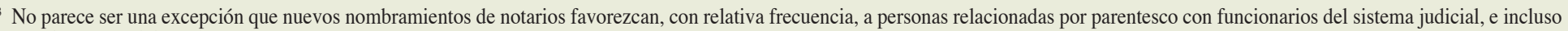
a notarios en servicio activo.

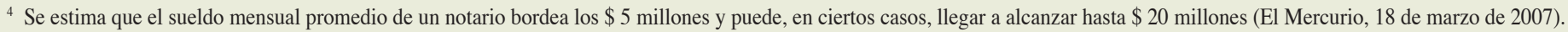

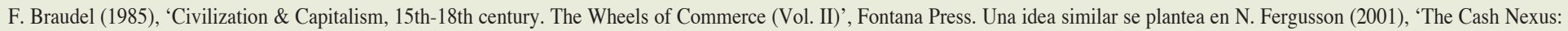
Money and Power in the Modern World, 1700 - 2000.' (ver cap. 2).
} 
explícita y legal, podría, tal vez, explicarse por una exitosa captura del regulador, que efectúa el grupo privado favorecido.

Pero quizás existan otras razones relacionadas con incentivar un uso eficiente de los recursos disponibles, que justifiquen la entrega de privilegios en cupos limitados y de forma vitalicia (tema independiente de su entrega 'gratuita'). El economista Joseph Schumpeter pensaba que la entrega de derechos monopólicos podía, en determinadas situaciones, promover el progreso económico. Pensaba en innovaciones que requieren grandes inversiones con valor de especificidad a la función provista bajo derecho monopólico. ${ }^{6}$ En este caso, las ganancias monopólicas serían necesarias para financiar tales inversiones.

No obstante lo anterior, cuesta imaginar 'grandes' inversiones del tipo antes referido que sean relevantes a la labor de los notarios en Chile. Similar escepticismo también se aplica, al menos según lo históricamente observado, a esfuerzos de innovación en el caso de otros roles de auxiliares de la administración de justicia, como son los receptores, el archivero judicial o incluso los conservadores. La impresión general sobre el rol jugado por la innovación en estos roles tiende a ser, más bien, la opuesta.

Si existiese algún grado de inversión con valor específico a la labor de los notarios, es del todo improbable que su financiamiento requiera un privilegio de carácter cuasi-vitalicio. En relación al todavía limitado número existente de cupos notariales, sugerimos que podría pensarse en 'liberalizar' tal condición, en algún grado parcial, sobre todo para aquellas funciones notariales más simples.

Por último, y en relación al sistema vigente de nombramientos y promociones de notarios, todos nuestros argumentos previos, junto con evidentes razones de equidad social e igualdad de oportunidades, señalan la clara conveniencia social de introducir reformas que insuflen mayor competencia y transparencia para acceder a este cargo, sea a través

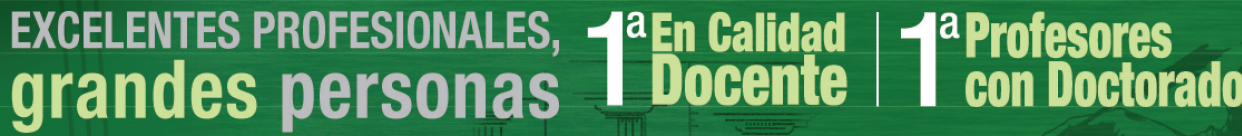

* Ranking de Universidades REVISTA QUE PASA, noviembre de 2006

Estudia Ingeniería Comercial e Ingeniería Comercial para Profesionales

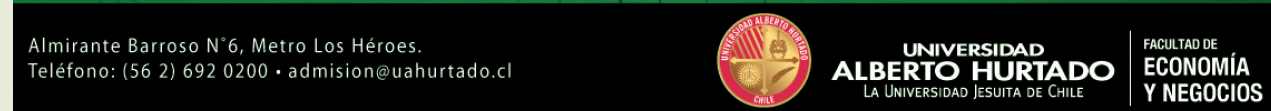

de un sistema de concurso público de antecedentes, riguroso y meritocrático, quizás complementado con un sistema de licitación pública para aquellos cupos más codiciados, o bien mediante la directa competencia en el mercado (esto último en relación a la oferta de las funciones notariales más simples).

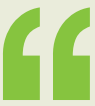

\section{Respecto de los trámites de} baja complejidad, el número de cupos disponibles para la función notarial asociada debiera decidirse por medio del mercado, y la adjudicación sujeta al cumplimiento y fiscalización de requisitos básicos de competencia, honorabilidad, inhabilidades e incompatibilidades. Estas funciones notariales más simples -autorizar firmas, declaraciones 0 cartas poderes; certificar supervivencia o estado civilno requieren que sea un abogado quien las provea.
Requisitos de nombramiento y especialización de funciones notariales

La exigencia de la profesión de abogado para ser nombrado notario en Chile guarda relación con las funciones y responsabilidades que se le exige a este rol.

En el sistema anglosajón el notario no requiere ser necesariamente abogado, por cuanto no tiene la función pública de ofrecer garantías jurídicas. En Estados Unidos, por ejemplo, los notarios ven limitada su función a la mera certificación de firmas. En este sistema, quienes deseen resguardarse del riesgo de que un determinado documento no sea auténtico, compran un seguro.

Por otro lado, las exigencias para ejercer la actividad de notario en Estados Unidos son objetivas, uniformes y no imponen costos de entrada excesivos. En diversos estados se requiere simplemente ser mayor de 18 años, rendir exitosamente un examen, recomendaciones que avalen la honorabilidad del postulante y llenar una solicitud. Las licencias para ejercer la función se otorgan por un plazo de cinco años. El número de notarios no está limitado por ley. Los notarios responden por sus errores indemnizando al usuario que se vea afectado, razón por la cual contratan seguros de responsabilidad. El sistema hace que exista una amplia oferta de servicios notariales; los trámites no suelen exceder el precio de dos dólares.

Probablemente el caso de España guarde una relación más cercana con el rol de notario definido en la ley chilena. Sin embargo, en España las exigencias para postular al cargo

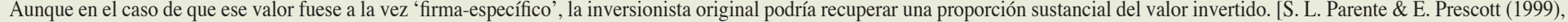
'Monopoly Rights: A Barrier to Riches'. American Economic Review 89(5): 1216-1233].

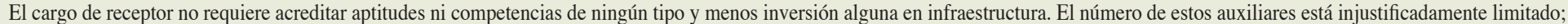
el sistema para acceder a la actividad es especialmente opaco y la fiscalización de su cometido poco eficaz.

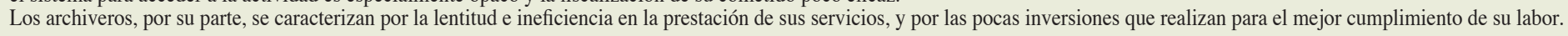


son evidentemente superiores, y bajo condiciones más transparentes y objetivas, que las vigentes en Chile. Junto con ser abogado, el postulante debe rendir varios exámenes ante un tribunal acreditador. Este último está compuesto por el Director General de los Registros y el Notariado, dos notarios, un profesor (catedrático o profesor titular) de derecho, un juez, un conservador de bienes raíces y un abogado con al menos quince años de experiencia. Los exámenes consisten en dos pruebas orales (públicas) y dos escritas (parte significativa de estas últimas también son de acceso público), sobre diversos temas específicos de derecho. La convocatoria a esta oposición pública define con transparencia los requisitos exigidos al postulante y el sistema o forma de calificación de aquellos. Es un hecho público y notorio en España que estos concursos constituyen una de las oposiciones públicas más difíciles y exigentes.

Una lección extraíble del liberal sistema imperante en Estados Unidos es la posibilidad de pensar en segmentar las funciones notariales según la complejidad de los trámites involucrados: se podría liberalizar, por un lado, aquellas funciones referidas a trámites de menor complejidad, dejándolas sometidas a la libre competencia de mercado; y por otro, se podría asignar a través de concurso público de antecedentes, o incluso vía licitación aquellos cupos más cotizados, las funciones que requieren conocimientos más complejos, quedando éstas, además, sujetas a mayor fiscalización del Estado.

Respecto de los trámites de baja complejidad, el número de cupos disponibles para la función notarial asociada debiera decidirse por medio del mercado, y la adjudicación sujeta al cumplimiento y fiscalización de requisitos básicos de competencia, honorabilidad, inhabilidades e incompatibilidades. Estas funciones notariales más simples -autorizar firmas, declaraciones o cartas poderes; certificar supervivencia o estado civil- no requieren que sea un abogado quien las provea. En el caso de las funciones asociadas a trámites más complejos, parece sensato mantener una regulación pública sobre el número total de cupos disponibles, de forma que éste guarde relación con criterios razonables de demanda, según sea el área geográfica, y que además permita una adecuada fiscalización.

En forma complementaria, podría revisarse la ley para rebajar las exigencias de utilizar obligatoriamente escrituras públicas para determinados negocios, de modo que el nivel de seguridad jurídica que las partes quieran dar a sus contratos sea optativo. Probablemente hoy existen exigencias redundantes de garantía notarial. Un ejemplo relacionado al problema de redundancia: el año pasado se implementó el uso de la firma electrónica para notarios y otros ministros de fe (Auto Acordado 163/06 de la Corte Suprema). Sin embargo, la normativa hace depender la validez de la firma electrónica de la certificación de autenticidad de un organismo distinto ( $\mathrm{y}$ adicional) al propio ministro de $\mathrm{fe}^{9}$ lo que implica una doble, e innecesaria, certificación de autenticidad.

\section{Aranceles y Fiscalización}

Las tarifas que los notarios debieran cobrar por sus servicios son fijadas cada cierto tiempo por el Ministerio de Justicia, y están basadas en criterios desconocidos que no parecen guardar relación con los costos de prestar dichos servicios o con criterios objetivos y transparentes.
En marzo de 2006 se dio a conocer el primer estudio realizado por encargo del Ministerio de Justicia para analizar la relación entre los aranceles notariales y los costos de proveer dicho servicio. Sin embargo, la metodología de ese estudio, realizado por abogados, no está explícita en el informe final. Las conclusiones señalan que algunos trámites tienen aranceles cuyo monto estaría por sobre sus costos, y otros por debajo. No queda claro, en todo caso, qué notarías se utilizaron para realizar este estudio, ni qué metodología se utilizó para definir la 'estructura de costos eficientes' para cada trámite (¿quizás una metodología similar al concepto de 'empresa eficiente' usado para tarificar servicios monopólicos?).

En todo caso, e independiente de lo que concluye el estudio mencionado, en la práctica se constata que el arancel máximo vigente no siempre es respetado. Sobre la base de un muestreo aleatorio realizado para efectos de este artículo, que consideró once notarías del centro de Santiago, separadas por unos pocos metros, se constataron diferentes precios para dos trámites sencillos: (i) una declaración jurada y (ii) un permiso para que el cónyuge salga del país con un hijo. En ambos casos, la desviación estándar en los precios observados bordea el $30 \%$ del valor promedio cobrado.

\section{Cuadro 1: Valores cotizados en 11 notarías del centro de Santiago (valores en pesos, junio de 2007)}

\begin{tabular}{lcc}
\hline & $\begin{array}{c}\text { Trámite \#1: } \\
\text { Declaración Jurada }\end{array}$ & $\begin{array}{c}\text { Trámite \#2: } \\
\text { Permiso de salida de hijo } \\
\text { al extranjero }\end{array}$ \\
\hline Valor Máximo & 3000 & 6000 \\
\hline Valor Mínimo & 1000 & 1500 \\
\hline Promedio & 2027,3 & 3590,9 \\
\hline $\begin{array}{l}\text { Desviación Estándard } \\
\text { (como \% del valor medio) }\end{array}$ & 581,5 & 1179,4 \\
\hline Arancel legal máximo & $(28,7 \%)$ & $(32,8 \%)$ \\
\hline
\end{tabular}

Fuente: elaboración propia en base a muestreo aleatorio realizado en el centro de Santiago.

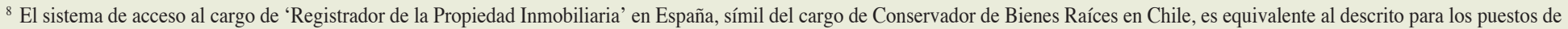
notario.

${ }^{9}$ La ley 19.799 y su reglamento establecen que depende de un prestador acreditado de servicios de certificación. 
Sobre la base de un muestreo aleatorio realizado para efectos de este artículo, que consideró once notarías del centro de Santiago, separadas por unos pocos metros, se constataron diferentes precios para dos trámites sencillos: (i) una declaración jurada y (ii) un permiso para que el cónyuge salga del país con un hijo. En ambos casos, la desviación estándar en los precios observados bordea el $30 \%$ del valor promedio cobrado.

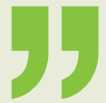

El decreto que fija los aranceles de los notarios establece que los afectados por el incumplimiento de los mismos pueden reclamar en la intendencia o gobernación respectiva o ante el ministro visitador que corresponda. ${ }^{10} \mathrm{La}-$ mentablemente, la ley chilena no contempla sanciones monetarias para estas infracciones y sólo considera algunas disciplinarias, de infrecuente aplicación, como amonestación, censura o suspensión del ejercicio del cargo. Una de las interrogantes que surgen al respecto es por qué existen estas instancias de reclamo administrativas, especiales y poco eficaces, en lugar de dar plena aplicación a estatutos que ya existen y que se ocupan de las relaciones mercantiles y civiles, como por ejemplo, la legislación de protección del consumidor.

Adicionalmente, muchas notarías ni siquiera tienen a la vista de los consumidores el correspondiente arancel, por lo que es difícil para éstos colaborar con la fiscalización que debiera realizar la autoridad. Los notarios se encuentran bajo la supervigilancia de un representante de la Corte de Apelaciones o del juez de letras respectivo, según corresponda. Esta fiscalización consiste, teóricamente, en una visita que cada dos meses realiza el funcionario designado. Es evidente, sin embargo, que los jueces están lejos de ser expertos en fiscalización, ni mucho menos poseer ventajas comparativas para destinar su tiempo a estas labores.

En otros países, como Colombia, existen superintendencias que fiscalizan al notariado y a quienes cumplen labores registrales. Ello facilita fiscalizar con personal más idóneo, junto con mantener bases de datos registrales para ser usadas por los consumidores, construidas con el aporte de los mismos fiscalizados.

\section{Los conservadores}

Los registros de propiedad sirven para otorgar certeza y seguridad jurídica sobre la propiedad de bienes muebles, como es el caso del registro de vehículos motorizados -a cargo del Registro Civil- y de los de marcas y patentes -del Departamento de Propiedad Industrial del Ministerio de Economía-, o acerca del dominio sobre bienes inmuebles, como es el caso de los conservadores de bienes raíces. Todos ellos registran transacciones que tienen por objeto estos bienes, como también gravámenes que pesan sobre ellos.

Existen dos formas genéricas de registrar la propiedad de un bien raíz: aquellas que tienen como objeto central el inmueble y que

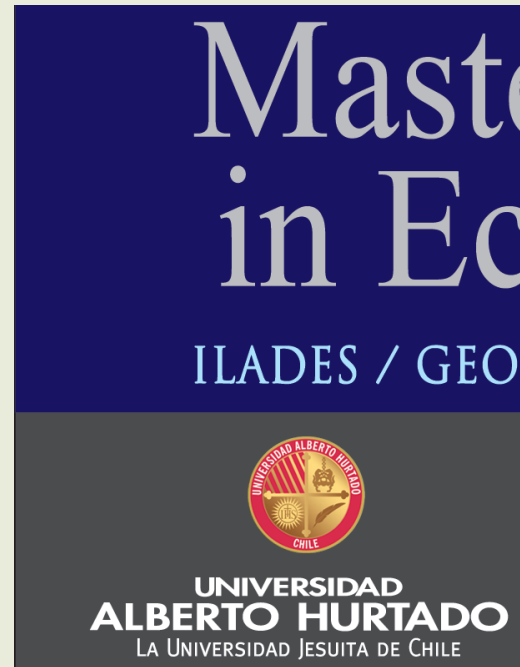

LA UNIVERSIDAd Jesuita de ChILE

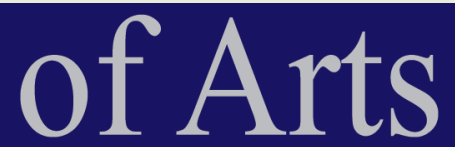

O ics

\section{GEORGETOWN UNIVERSITY}

El Programa de Postgrado en Economía es conducente

al grado académico de "Master of Arts in Economics" (MAE),

que otorga Georgetown University y al grado de Magíster

en Economía que otorga la Universidad Alberto Hurtado.

\section{El programa presenta tres variantes:}

- Programa General

- Programa con Mención en Políticas Sociales (Public Economics)

- Programa con Mención

en Economía de Empresas (Business Economics). 
registran las transacciones y gravámenes que se generan a su respecto (registros reales); y las que se basan en las personas: se registran las propiedades y transacciones que ellas realizan respecto de inmuebles (registros personales). El primer tipo de registros facilita la búsqueda y estudio de la historia de una determinada propiedad. El segundo permite conocer con mayor facilidad el patrimonio inmobiliario de una persona en particular, lo que puede resultar útil para un acreedor, por ejemplo. En Chile sólo se utilizan registros de tipo personal, sistema que rige desde su implementación original en 1857.

Los conservadores en Chile son ministros de fe encargados de los registros conservatorios de bienes raíces, de comercio, de minas, de accionistas de sociedades mineras, de propiedad de aguas, de prenda agraria, de prenda industrial y de otros.

Los conservadores no disponen de atribuciones y herramientas que les permitan comprobar verdaderamente la validez y eficacia de los títulos que anotan en su registro (por ejemplo, un aporte a una sociedad o un contrato de compra venta); así, el conservador hace fe de que una propiedad está inscrita a nombre de una persona, pero no de que esa persona sea legalmente dueña del inmueble en cuestión; ${ }^{11}$ el conservador tampoco comprueba que los deslindes de un bien raíz correspondan a la realidad, limitándose, en los hechos, a reproducir los consignados en el último título referente a la propiedad en cuestión anotado en su registro. ${ }^{12}$

En todo caso, los conservadores pueden ser condenados por la justicia a indemnizar a quienes causen perjuicios en razón de actos concernientes al desempeño de su labor. Sería interesante poder comparar el importe de la prima de un seguro de responsabilidad civil de un conservador determinado con el monto de sus utilidades. A priori, no parece razonable que la justificación de este privilegio pueda radicar en un premio por el riesgo y responsabilidad de la actividad. Algunas luces al respecto arroja el hecho de que la ley establece que notarios, conservadores y archiveros deben rendir una fianza "igual al monto del sueldo anual que la ley fije para los efectos de su jubilación" para responder de las indemnizaciones y otros pagos a los que sean condenados en el ejercicio de su cargo durante todo el período para el que son nombrados. ${ }^{13}$

\section{Sistema de Nombramiento}

La ley establece que habrá un conservador en cada comuna, o grupo de comunas, que constituya el territorio jurisdiccional de un juzgado de letras, nombrado mediante idéntico mecanismo que el descrito arriba para los notarios.

En la comuna de Santiago, un conservador presta servicios para todo el territorio jurisdiccional de la Corte de Apelaciones de Santiago. Es una sola oficina, pero sus funciones son desempeñadas por tres funcionarios: un conservador del registro de propiedad, que se encarga también de los registros de comercio, de prenda industrial, de prenda agraria y de propiedad de aguas; un segundo conservador se encarga de los registros de hipotecas y gravámenes y un tercer conservador tiene bajo su responsabilidad el registro de interdicciones y prohibiciones de enajenar y un registro especial de prenda.

En algunas otras ciudades, como Valparaíso o Viña del Mar, también existen conservadores de dedicación exclusiva. Para la mayoría de las comunas o agrupaciones de comunas del país, el Presidente de la República designa entre los notarios que existen en cada lugar, el que quedará a cargo del registro de minas, el de accionistas de sociedades mineras, del registro de bienes raíces y también del de propiedad de aguas, prenda agraria, prenda industrial y especial de prendas. En los territorios donde exista sólo un notario, el Presidente puede disponer que también ejerza el cargo de conservador de todos los registros.

Los conservadores, en Chile, constituyen verdaderas empresas unipersonales que son concesionarias del Estado. Sus empleados no tienen el carácter de funcionarios públicos. Asimismo, los cargos de conservador poseen carácter cuasi-vitalicio. ${ }^{14}$ No existe razón alguna de eficiencia asignativa para entregarlos de esta manera. Ni las inversiones requeridas (manejo de bases de datos), ni los incentivos productivos necesarios para una adecuada provisión de estos servicios, necesitan que se les asegure retornos 'de por vida'.

\section{Los conservadores, en Chile, constituyen verdaderas empresas unipersonales que son concesionarias del Estado. Sus empleados no tienen el carácter de funcionarios públicos. Asimismo, los cargos de conservador poseen carácter cuasi-vitalicio. No existe razón alguna de eficiencia asignativa para entregarlos de esta manera.}

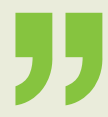

Actualmente existen funciones registrales que están bajo administración estatal. Por ejemplo, el Registro de Vehículos Motorizados es administrado por el Registro Civil (función que estaba en manos del Conservador de Bienes Raíces durante la primera

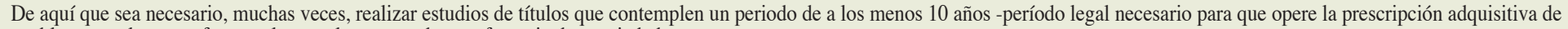
inmuebles- que elevan en forma relevante los costos de transferencia de propiedades.

${ }^{12}$ Es por ello que se producen inscripciones dobles, se superponen deslindes de propiedades y otras confusiones de naturaleza semejante.

Artículo 473 del Código Orgánico de Tribunales.

${ }^{14}$ A los conservadores también se les aplica la reforma de 1995 que definió como edad máxima de ejercicio para este cargo los 75 años.
} 
mitad del siglo XX). Otros ejemplos son el Departamento de Propiedad Industrial del Ministerio de Economía, y el Instituto de Salud Pública. La percepción general es que estos registros funcionan razonablemente bien y cobran tarifas aceptables.

Sin cuestionar las posibles ganancias asignativas asociadas a la administración por parte de privados de al menos parte de los servicios registrales, es evidente que se requiere introducir genuina competencia para acceder a la concesión privada de estos servicios. Hoy, la percepción general es que la administración privada de estas concesiones está asociada con ausencia de innovación y de mejoras sustanciales en la calidad de los servicios provistos y que las tarifas parecieran ser excesivas.

\section{Aranceles cobrados}

Los usuarios de los servicios de los conservadores pagan según aranceles que fija el Ministerio de Justicia. No existe información disponible sobre los parámetros usados para determinar estas tarifas; menos aún evidencia si éstas son fijadas sobre la base de los costos de prestar tales servicios.
Los conservadores han sido criticados como responsables de generar importantes aumentos en los costos de transacción requeridos para realizar operaciones inmobiliarias. $\mathrm{La}$ Cámara Chilena de la Construcción, en un estudio divulgado el año $2006^{15}$, estimó en US\$ 7,6 millones las pérdidas anuales de las empresas inmobiliarias imputables a los costos de realizar los estudios de títulos necesarios para sus proyectos, los que sólo se justificarían por las deficiencias existentes en los registros de los conservadores de bienes raíces (CBR). Cabe también recordar, como ya vimos, que las inscripciones en el CBR representan un porcentaje importante de los costos operacionales asociados a la compraventa de un bien inmueble.

Relacionado a este argumento de costos 'excesivos', podría quizás pensarse en eliminar determinados actos jurídicos como condición exigida para que ciertos negocios sean válidos. Por ejemplo, la exigencia legal de realizar la compraventa de inmuebles mediante escrituras públicas, las que deben ser posteriormente inscritas en el respectivo conservador, pareciera constituir una duplicidad innecesaria. Lo mismo se aplica a la constitución de sociedades comerciales. En ambos casos, ¿qué necesidad jurídica hay de comparecer ante un ministro de fe para la suscripción de un contrato, y luego ante otro para el registro de dicho acto jurídico? ¿No es menos costoso y más eficiente que dicho acto jurídico se celebre de una vez frente al mismo ministro de fe encargado de su registro? Ciertamente la integración de algunas de las funciones notariales y registrales contribuiría a lograr servicios más 'costo efectivo'.

\section{Licitación pública para asignar esta concesión}

Las funciones de los conservadores debieran asignarse vía licitación pública. Podrían adjudicarse a quienes hagan las mejores propuestas. Quienes otorguen la licitación deberían ponderar aspectos relacionados con la calidad del servicio registral y el valor de las tarifas ofertadas, y quizás incluso ampliar el número de conservadores para así facilitar una oportuna y expedita atención a los ciudadanos. ${ }^{16}$ Asimismo, no se percibe razón alguna para que la licitación se limite sólo a personas naturales y menos que se exija ser abogado. Adicionalmente, debieran aumentar los niveles de fiscalización y encomen-

Publicación Fundamenta, № 16, año 2006 (http://www.cchc.cl/DATA/Fotos_Link/Fundamenta16C.pdf)

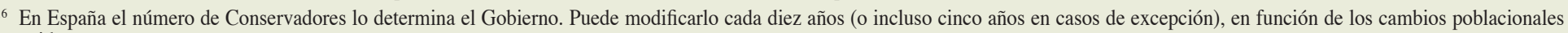
ocurridos.

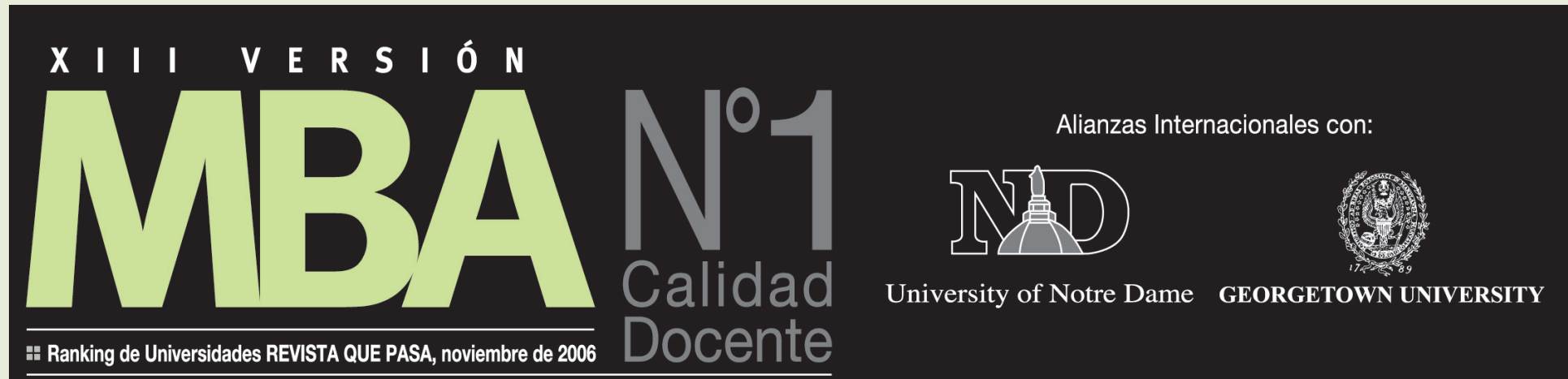

INICIO DE CLASES

20 de abril - Clases viernes y sábados cada tres semanas Almirante Barroso N ${ }^{\circ} 6$, Los Héroes mba@uahurtado.cl • www.uahurtado.cl/mba

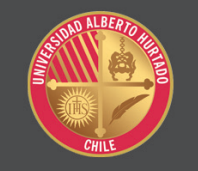

UNIVERSIDAD
ALBERTO HURTADOO
LA UNIVERSIDAD JESUITA DE CHILE FACULTAD DE ECONOMÍA Y NEGOCIOS 
darse ésta a una repartición especializada del Estado, y derogar la dependencia del Poder Judicial de estos funcionarios.

El uso de licitaciones públicas reduciría el riesgo de nepotismo y endogamia. En efecto, ante la supresión del pago en dinero que antaño se hacía por estos cargos, tal como ocurría con los puestos de notario, surge el riesgo de que el pago monetario sea reemplazado por otras prestaciones, como la contratación de parientes o amigos de quienes intervienen en el nombramiento. $\mathrm{Al}$ respecto, Paredes ${ }^{17}$ plantea: "Los conservadores del registro de bienes inmuebles han sido, por lo general, personas vinculadas a la alta jerarquía política y judicial”. Entre los conservadores nombrados hace menos tiempo se encuentran hijos y parientes directos de algunos senadores y diputados. El actual conservador a cargo del Registro de Propiedad en Santiago es hijo de un ex-presidente de la Corte Suprema y hermano de una fiscal actual de dicha corte, dos de cuyos hijos trabajan hoy en el CBRS.

\section{Desafíos de Modernización}

En los últimos años se han observado algunos esfuerzos por modernizar la gestión de los noventa conservadores agrupados en la Asociación de Notarios y Conservadores de Chile. La Corporación Chilena de Estudios de Derecho Registral ha impulsado algunas medidas para introducir medios informáticos a su labor. Por ejemplo, se ha creado una suerte de "mesón virtual" que permite solicitar algunos registros on line. Sin embargo, los tiempos de respuesta son todavía prolongados, medidos desde que se solicita el documento hasta que éste se recibe físicamente (no se envía por correo electrónico ni puede imprimirse desde una página web).

\section{Los usuarios de los servicios de los conservadores pagan según aranceles que fija el Ministerio de Justicia. No existe información disponible sobre los parámetros usados para determinar estas tarifas; menos aún evidencia de si éstas son fijadas sobre la base de los costos de prestar tales servicios.}

5

No obstante, se requiere informatizar de forma generalizada estos registros y propender a un sistema computacional en línea. No existe razón para continuar usando principalmente libros para realizar y mantener las inscripciones. Asimismo, sería conveniente avanzar hacia una interconexión plena entre todos los conservadores del país, generando una base de datos unificada a nivel nacional. Se ha propuesto incluso incorporar otras tecnologías a los registros de la propiedad raíz, por ejemplo el Sistema de Posicionamiento Global (GPS) y el uso intensivo de firma electrónica avanzada para la emisión de certificados on line.

Los problemas de gestión de información de los conservadores parecen tener su raíz en el propio sistema registral que se utiliza. El sistema de registro personal mantiene en forma dispersa las inscripciones de un mismo bien raíz en múltiples registros; por tanto dificulta mantener información fácilmente consultable sobre la historia de la propiedad de un bien raíz. Es más práctico que se mantenga, tal como ocurre en países como España, Alemania, Austria o Suiza, la historia de la propiedad recaída sobre cada inmueble en una sola hoja del respectivo registro (registro real). Esto no implica deshacerse del registro personal. La tecnología informática permite llevar ambos registros en paralelo, sin duplicar esfuerzos. La existencia de un sistema registral como el propuesto facilitaría la mantención de un sistema catastral de características y usos del territorio.

Para incentivar avances más rápidos y más de fondo en las áreas de innovación sugeridas, es fundamental, primero, reformar el sistema actual de nombramiento de los conservadores. Ello, por cuanto sólo la libre y transparente competencia de mercado podrá garantizar que sean los más competentes en proveer estos servicios quienes en verdad logren adquirir este derecho concesional.

\section{Mensaje Final}

Resulta evidente la necesidad de introducir más competencia, meritocrática y transparente, en los sistemas de asignación de los diversos roles de 'auxiliares de la administración de la justicia'. De lo contrario, y junto a las obvias inequidades resultantes, se seguirá cumpliendo lo hace ya mucho tiempo vaticinado por Adam Smith en su Riqueza de las Naciones, en el sentido que los derechos monopólicos protegen a los favorecidos con tal privilegio de "la superior vigilancia y atención de adventurers ('emprendedores') privados..." Así, en el largo plazo, "la entrega de derechos monopólicos sólo sirve para apoyar la negligencia, derroche y malversación del grupo privilegiado". 